\title{
Pengaruh Temperatur dan Arus Listrik Proses Elektroplating Krom Pada Plastik ABS
}

\author{
(The Effect of Temperature and Electric Current Chrome Electroplating \\ Process on ABS Plastics) \\ Muhammad Budi Nur Rahman ${ }^{a}$, Bambang Riyanta ${ }^{b}$, Delvis Agusman ${ }^{c}$ \\ ${ }^{\mathrm{a}, \mathrm{b}}$ Mechanical Engineering Department, Universitas Muhammadiyah Yogyakarta \\ Jl. Brawijaya, Tamantirto, Kasihan, Bantul, Yogyakarta, Indonesia 55183 \\ Telephone/fax +62(0274) 387656/ (0274) 387 646/ 081215079748 \\ e-mail: budinurrahman@umy.ac.id \\ ${ }^{9}$ Mechanical Engineering Department, Universitas Muhammadiyah Prof. Dr. HAMKA \\ Jalan Tanah Merdeka, Jakarta Timur, DKI Jakarta, Indonesia, 13830 \\ Telephone/fax +62(021) 8400341/ 0812-916-7463 \\ e-mail: delvis.agusman@gmail.com
}

\begin{abstract}
Abstrak
Tujuan penelitian ini adalah mengetahui pengaruh temperatur dan arus listrik proses elektroplating krom terhadap ketebalan lapisan dan kekasaran permukaan. Proses elektroplating pada plastik $A B S$ diawali dengan proses etching, proses metalisasi palladium, dan electrolessplating nikel. Variasi arus proses elektroplating krom yang dilakukan adalah $11 \mathrm{~A}, 16 \mathrm{~A}$, dan $22 \mathrm{~A}$ sedangkan variasi temperatur adalah $55^{\circ} \mathrm{C}, 65^{\circ} \mathrm{C}$, dan $75^{\circ} \mathrm{C}$. Pengamatan hasil pelapisan meliputi pengamatan struktur mikro menggunakan mikroskop optic dan $S E M$, ketebalan lapisan, kekasaran permukaan dan kekerasan permukaan. Semakin besar arus proses elektroplating dapat meningkatkan kekasaran permukaan dan ketebalan lapisan. Proses elektroplating dengan arus $22 \mathrm{~A}$ menghasilkan kekasaran permukaan 0,493 $\mu \mathrm{m}$ dan ketebalan lapisan sebesar $60,61 \mu \mathrm{m}$. Peningkatan temperatur proses elektroplating sampai temperatur $75^{\circ} \mathrm{C}$ akan menurunkan nilai kekasaran permukaan sebesar $0,40 \mu \mathrm{m}$ dan ketebalan lapisan sebesar $21,53 \mu \mathrm{m}$. Variasi arus dan temperatur proses elektroplating tidak banyak berpengaruh terhadap nilai kekerasan yang berkisar antara 111 114 shore-D.
\end{abstract}

Kata kunci: arus listrik; temperatur; ketebalan; kekasaran, kekerasan.

\section{Abstract}

The purpose of this study was to determine the effect of temperature and electric current on the chrome electroplating process on the thickness of the layer and surface roughness. The electroplating process on ABS plastic begins with the etching process, the palladium metallization process, and the nickel electrolessplating. The variation of the chromium electroplating process current is $11 \mathrm{~A}, 16$ $A$, and $22 \mathrm{~A}$ while the temperature variation is $55^{\circ} \mathrm{C}, 65^{\circ} \mathrm{C}$, and $75^{\circ} \mathrm{C}$. Observation of coating results includes observation of microstructure using optical microscopy and SEM, layer thickness, surface roughness and surface hardness. Coating research results include observations of microstructure and SEM, layer thickness, surface roughness and surface hardness. The greater the current electroplating process can increase surface roughness, thickness of the layer. Electroplating process with a current of $22 \mathrm{~A}$ produces a surface roughness of $0.493 \mu \mathrm{m}$ and a layer thickness of $60.61 \mu \mathrm{m}$. Increasing the temperature of the electroplating process to a temperature of $75^{\circ} \mathrm{C}$ will reduce the surface roughness value by 0.40 $\mu \mathrm{m}$ and the thickness of the layer by $21.53 \mu \mathrm{m}$. The variation of current and temperature of the electroplating process does not significantly affect the hardness values ranging from 111 - 114 shore- $D$.

Keywords: electric current; temperature; thickness; roughness, hardness. 


\section{Pendahuluan}

Penggunaan plastik untuk menggantikan logam semakin banyak, seperti komponen mesin industri, komponen kendaraan, alat tulis, alat rumah tangga, mainan anak-anak maupun barang fashion. Untuk meningkatkan penampilan, plastik dapat dilapisi dengan logam. Penggunaan plastik memiliki keuntungan dibandingkan dengan logam, antara lain: ringan, tahan korosi, tahan gesekan, tahan cuaca, dan harga lebih murah. Pelapisan plastik dengan logam dapat dilakukan dengan metode elektroplating dan vacuum metallizing [1].

Proses elektroplating bisa diaplikasikan pada bahan thermoplastik karena ketahanan yang baik terhadap reaksi kimia. Salah satunya adalah plastic Acrylonitrile Butadiene Styrene (ABS) yang terdiri dari 3 monomer yaitu Acrylonitrile, Butadiene dan Styrene. Acrylonitrile bersifat tahan terhadap reaksi bahan kimia dan stabil terhadap panas tinggi, Butadiene dapat meningkatkan ketangguhan (toughness) dan sifat ketahanan impak, sementara itu styrene memiliki sifat mudah dibentuk, diproses dan meningkatkan kekakuan (rigidity). Plastik $A B S$ dapat dicetak dengan injection molding untuk membentuk benda yang diinginkan. Plastik $A B S$ dapat dielektroplating untuk memberikan efek dekoratif dengan terlebih dahulu dilakukan tahap metalisasi. Banyak jenis plastik $A B S$ yang terdapat di pasaran. Ada beberapa macam, namun tidak semua plastik $A B S$ dapat diproses elektroplating. Saat diproses elektroplating, agar tidak mengalami kegagalan, maka pilihlah jenis plastik $A B S$ dengan grade elektroplating. Dibandingkan dengan jenis plastik yang lainnya, plastik $A B S$ merupakan jenis plastik yang mempunyai faktor keberhasilan lebih besar untuk diplating. Hal tersebut disebabkan karena mudahnya permukaan plastik $A B S$ dietsa secara kimiawi. Plastik $A B S$ dapat dielektroplating karena memiliki kelebihan daya ikat yang kuat, dan memberikan kesan logam setelah dielektroplating. Kelebihan plastik $A B S$ antara lain mudah dibentuk melalui teknik injeksi molding, tidak terpengaruh perubahan cuaca, tahan abrasi, dan harga yang lebih murah dibandingkan dengan logam. Kelemahan dari plastik $A B S$ adalah memiliki kekerasan yang rendah, tidak tahan gesekan dan tidak tahan panas. Kelemahan tersebut dapat diatasi dengan pelapisan dengan nikel pada plastik $A B S$ yaitu dengan metode elektroplating. Proses elektroplating adalah proses menempelkan logam pada permukaan benda secara elektrokimia. Syarat utama agar suatu benda dapat dielektroplating adalah benda tersebut telah memiliki permukaan yang bersifat konduktif (pengantar) arus listrik yang baik atau disebut dengan proses elctrolessplating. Proses electrolessplating juga dapat meningkatkan nilai kekerasan permukaan, apalagi jika menggunakan nikel sebagai bahan pelapis. Logam merupakan jenis bahan yang mempunyai sifat yang sebagai material konduktor. Dengan demikian, benda kerja yang terbuat dari logam akan mudah untuk dielektroplating. Decorative chrome plating merupakan rangkaian yang tidak terpisahkan antara tahap elektroplating nikel dan elektroplating krom.

Proses elektroplating pada plastik hampir sama dengan elektroplating pada logam. Elektroplating pada plastik didahului dengan persiapan awal (proses metalisasi) meliputi tahap soap cleaning untuk menghilangkan lemak, tahap etching untuk membentuk permukaan berpori, tahap netralisasi untuk menghilangkan sisa cromic acid yang tersisa di permukaan plastik, tahap aktivasi agar plastik bersifat katalisator dengan palladium timah kompleks, dan electrolessplating nikel untuk membentuk plastik bersifat konduktif. Proses aktivasi dilakukan dengan pencelupan dalam larutan Palladium Chlorida dan larutan Stannous Chlorida dilanjutkan proses electrolessplating nikel pada plastik ABS. [2]

Proses etsa (etching) adalah proses yang menentukan daya lekat logam pelapis dengan plastik. Proses etsa akan membentuk permukaan plastik menjadi porous akibat reaksi kimia pada ikatan rangkap monomer penyusun plastik $A B S$. Permukaan yang berpori mempengaruhi tingginya daya ikat adhesi antara plastik $A B S$ dengan logam pelapis. Tahap etsa merupakan tahap yang paling penting untuk pembentukan pori-pori agar meningkatkan daya lekat lapisan serta menghasilkan permukaan yang tidak bersifat konduktif menjadi bersifat konduktif atau disebut dengan tahapan metalisasi (aktivasi palladium), sehingga logam pelapis dapat berikatan dengan baik pada plastik $A B S$. [3]

Kuat arus listrik pada proses elektroplating mempengaruhi massa lapisan dan ketebalan lapisan yang terbentuk. Ketebalan lapisan terbesar diperoleh pada saat menggunakan arus listrik 8 A selama 60 menit sebesar $0,109 \mathrm{~mm}$, sedangkan penggunaan arus listrik 4 A selama 30 menit menghasilkan ketebalan lapisan sebesar 0,026 mm. Hal ini juga sebanding dengan massa logam yang menempel pada plastik. Massa logam yang menempel pada penggunaan arus listrik 8 A selama 60 menit sebesar 4,852 gram, 
sedangkan penggunaan arus listrik $4 \mathrm{~A}$ selama 30 menit massa yang menempel sebesar $1,190 \mathrm{gram}$. Semakin besar kuat arus yang digunakan dan semakin lama waktu proses yang dilakukan, maka semakin besar nilai ketebalan dan massa lapisan yang terbentuk. Semakin besar kuat arus listrik yang digunakan menyebabkan elektron lebih reaktif (lebih mudah bergerak) sehingga dapat meningkatkan porsi akumulasi pergerakan elektron dan transfer material pada kedua elektroda. Besarnya energi listrik yang dibangkitkan di antara kedua elektroda (anoda dan katoda/specimen) digunakan untuk membangkitkan pergerakan elektron dan termasuk transfer material di antara keduanya yang diangkut oleh ion-ion bermuatan listrik melalui larutan. [4]

Lama waktu dan temperatur proses electrolessplating mempengaruhi ketebalan lapisan logam yang dihasilkan. Ketebalan terendah terdapat pada proses elektroles dengan temperatur $30^{\circ} \mathrm{C}$, waktu elektroles 5 menit dengan ketebalan sebesar $2,29 \mu \mathrm{m}$. Sementara itu, lapisan paling tebal terdapat pada proses elektroles dengan temperatur $50^{\circ} \mathrm{C}$, waktu elektroles 15 menit dengan ketebalan sebesar $4,79 \mu \mathrm{m}$. Semakin lama waktu proses elektroplating dan semakin tinggi temperatur yang digunakan menyebabkan ketebalan lapisan semakin meningkat. Lama waktu pencelupan akan mempengaruhi banyaknya logam nikel yang terikat pada permukaan plastik yang telah mengalami aktivasi paladium. Selain waktu, penggunaan temperatur yang lebih tinggi dapat mempertebal lapisan yang terbentuk dibandingkan dengan menggunakan temperatur lebih rendah. Hal ini disebabkan oleh laju reaksi (pergerakan ion-ion) dalam larutan elektrolit semakin cepat ketika temperatur dinaikkan. Akan tetapi peningkatan temperatur ini sebaiknya dilakukan pada batas yang diijinkan. [5]

Semakin bertambahnya temperatur cairan proses elektroplating nikel krom pada baja karbon rendah ST40, maka ketebalan dan kekerasan akan semakin meningkat. Pelapisan nikel-krom meningkatkan nilai kekerasan dari 254,3 $\mathrm{HB}_{30}$ menjadi $338,3 \quad \mathrm{HB}_{30}$ pada temperatur proses elektroplating $40^{\circ} \mathrm{C}$. Nilai kekerasan meningkat sampai temperatur elektroplating $55^{\circ} \mathrm{C}$ sebesar $354 \mathrm{HB}_{30}$ sedangkan pada temperatur $60^{\circ} \mathrm{C}$ terjadi penurunan nilai kekerasan menjadi $345,3 \quad \mathrm{HB}_{30}$. Proses elektroplating pada temperatur $55^{\circ} \mathrm{C}$ menghasilkan endapan yang optimum. Hal ini disebabkan oleh konduktivitas arus listrik untuk mobilitas ion-ion krom menuju katoda. Semakin tinggi temperatur pelapisan, maka semakin cepat ion-ion krom menempel pada permukaan spesimen, sehingga lapisan krom lebih padat yang menyebabkan kerapatan permukaan pada spesimen meningkat. Temperatur pelapisan mencapai optimum pada temperatur $55^{\circ} \mathrm{C}$ dan apabila dinaikkan lagi dapat menurunkan nilai kekerasan permukaan spesimen. [6]

Peningkatan kuat arus listrik, lama waktu proses elektroplating, dan konsentrasi larutan chromate acid mempengaruhi hasil pelapisan krom dengan plastik $A B S$. Nilai tertinggi untuk ketebalan lapisan, ketahanan aus, dan kekerasan, diperoleh pada arus 6 A dan waktu pelapisan 15 menit, demikian juga dengan kekasaran pemukaan. Hal ini menyebabkan meningkatnya jumlah kandungan chrome pada larutan, kuat arus dan waktu proses. [7].

Informasi pengaruh variasi temperatur dan arus listrik proses elektroplating krom pada plastik $A B S$ masih sangat jarang diperoleh. Mengetahui pengaruh arus listrik dan temperatur larutan dalam proses elektroplating krom pada plastik ABS terhadap nilai kekasaran permukaan, nilai kekerasan dan ketebalan lapisan menjadi tujuan dari penelitian ini.

\section{Metode}

Penelitian ini menggunakan plastic Acrylonitrile Butadiene Styrene (ABS) yang berbentuk spesimen uji tarik seperti pada Gambar 2.1 sesuai cetakan (mold) yang dimiliki oleh laboratorium Teknologi Plastik UMY. Spesimen dicetak dari bijih plastik ABS murni.

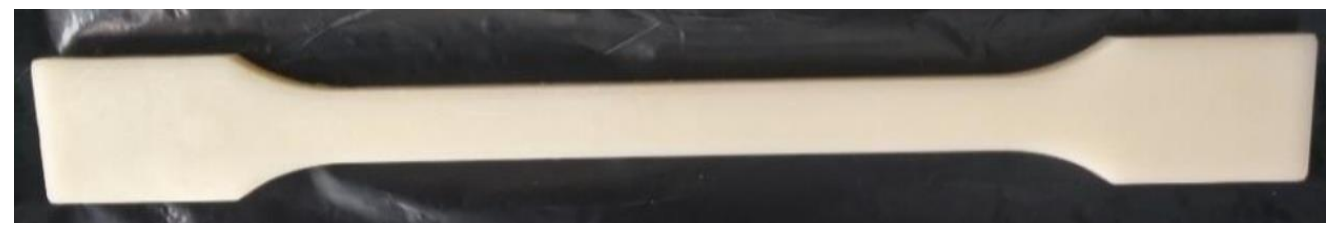

Gambar 2.1 Material ABS yang digunakan penelitian. 

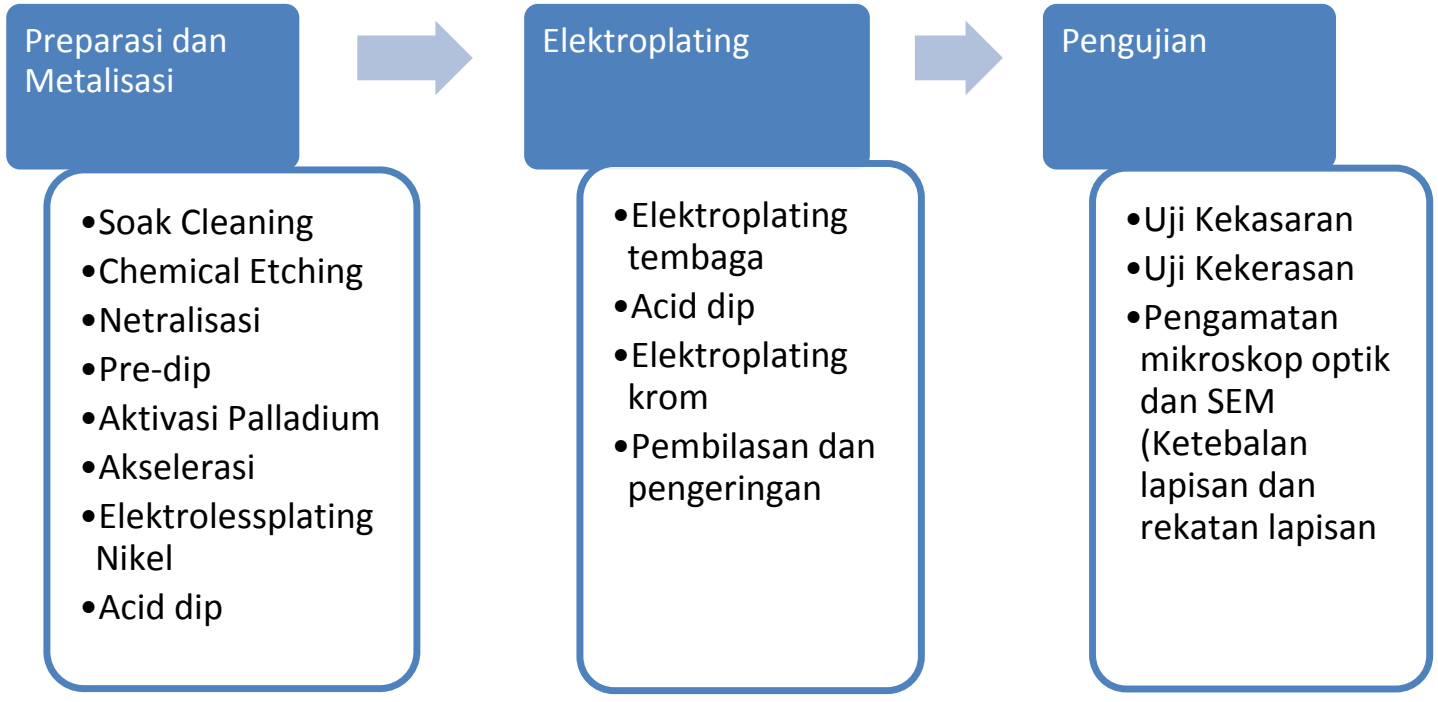

Gambar 2.2 Alur peneltian yang dilakukan

Gambar 2.2 adalah prosedur penelitian yang dilakukan. Proses persiapan diawali dengan proses soak cleaning untuk menghilangkan kotoran dan lemak yang menempel pada material. Proses etching menggunakan larutan chromic acid untuk membentuk permukaan plastik $A B S$ berpori-pori agar lapisan logam terikat kuat. Proses netralisasi menggunakan asam klorida untuk menghilangkan chromic acid yang tersisa di permukaan plastik. Proses aktivasi Palladium menggunakan larutan Palladium Chlorida dan larutan Stannous Chlorida untuk menghasilkan lapisan metalisasi permukaan plastik. Proses dilanjutkan dengan proses akselerasi dengan bahan akselerator dan eletrolessplating nikel.

Proses elektroplating tembaga menggunakan larutan copper sulfat $\left(\mathrm{CuSO}_{4}\right)$, asam sulfat $\left(\mathrm{H}_{2} \mathrm{SO}_{4}\right)$, asam klorida $(\mathrm{HCl})$, dan Brightener $\mathrm{AC}-01$, yang selanjutnya ditambahkan aquades sampai volumenya 1 liter. Proses pelapisan dilakukan pada temperatur ruangan, tegangan 1,5-3 V dengan arus $6 \mathrm{~A}$. Proses elektrolit krom menggunakan chromic acid $\left(\mathrm{H}_{2} \mathrm{CrO}_{4}\right)$ asam sulfat $\left(\mathrm{H}_{2} \mathrm{SO}_{4}\right)$ katalis DC-02 selanjutnya ditambahkan dengan aquades sampai volumenya 1 liter. Proses ini menggunakan tegangan $6 \mathrm{~V}$, dengan variasi temperatur $55^{\circ} \mathrm{C}, 65^{\circ} \mathrm{C}$, dan $75^{\circ} \mathrm{C}$. Selain itu variasi arus yang digunakan yaitu $11 \mathrm{~A}, 16 \mathrm{~A}$, dan $22 \mathrm{~A}$.

Pengujian Material:

1) Pengujian kekasaran permukaan dilakukan untuk mengetahui kerataan dan kehalusan permukaan hasil elektroplating. Pengujian menggunakan Surface Roughness Tester tipe DR220 dilakukan dengan pengulangan 5 titik dengan panjang pengukuran $2,5 \mathrm{~mm}$.

2) Pengujian kekerasan untuk mengukur ketahanan material terhadap penetrasi benda terstandar menggunakan shore hardness tester (durometer) tipe D. Nilai kekerasan diperoleh dari ketahanan permukaan material terhadap penetrasi jarum stylus durometer dengan beban yang telah ditentukan. Durometer dapat digunakan untuk mengukur material non logam seperti: kaca, akrilik, resin, ebonite maupun fiber.

3) Pengamatan ikatan lapisan menggunakan alat Scanning Electron Microscope (SEM). Pengukuran ketebalan lapisan menggunakan Metallurgical Microscope Optic Olympus BX53M dan juga untuk mengamati struktur mikro plastik dengan lapisan permukaan hasil pelapisan.

\section{Hasil dan Pembahasan}

\subsection{Hasil Pelapisan}

Hasil pelapisan logam pada plastik $A B S$ terlihat seperti pada Gambar 3.1. Gambar nomor 1 adalah material plastik $A B S$ yang akan diproses, dibuat dari bijih plastik $A B S$ murni yang dicetak dengan mesin injection moulding yang ada di Laboratorium Teknologi Plastik Prodi Teknik Mesin UMY. Gambar nomor 2 adalah hasil electrolessplating nikel yang 
sebelumnya dilakukan persiapan dengan proses etching, netralisasi, pre-dip, aktivasi palladium, akselerasi, dan electrolessplating nikel. Terlihat adanya perubahan warna menjadi hitam dan sudah bersifat konduktor yang siap untuk dilakukan proses electroplating. Gambar nomor 3 adalah hasil electroplating tembaga menghasilkan warga kemerahmerahan. Penggunaan tembaga sebagai pelapis dasar dapat menaikkan kekerasan dan ketangguhan lapisan yang terjadi [8]. Gambar nomor 4 adalah hasil elektroplating krom menghasilkan warna keperakan. Proses elektroplating krom dilakukan dengan variasi arus sebesar $11 \mathrm{~A}, 16 \mathrm{~A}$, dan $22 \mathrm{~A}$. Variasi temperatur proses elektroplating yang dilakukan adalah $55^{\circ} \mathrm{C}, 65^{\circ} \mathrm{C}$, dan $75^{\circ} \mathrm{C}$. Dalam beberapa kali proses pelapisan terjadi kegagalan terutama pada proses electrolessplating nikel, di mana proses etching memegang peranan yang paling penting terjadinya ikatan antara plastik dan logam pelapis. Apabila lapisan electroless nikel berhasil baik dan rata maka pelapisan tembaga dan krom akan berhasil.

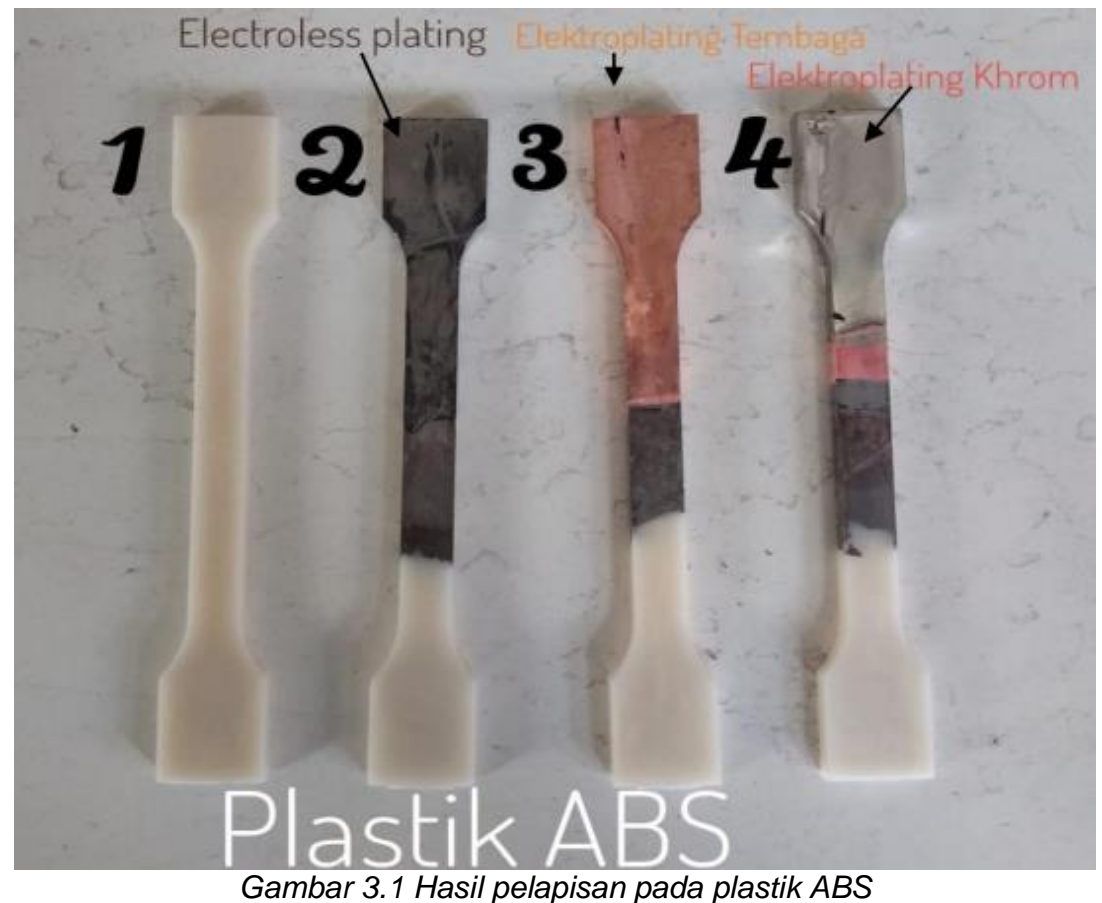

\subsection{Ketebalan Lapisan}

Hasil pengamatan pelapisan logam nikel, tembaga, dan krom plastik $A B S$ dengan metode elektroplating dapat dilihat pada Gambar 3.2. Pelapisan diawali dengan proses etsa untuk membentuk permukaan berpori agar lapisan logam nikel dapat terikat kuat pada plastik dengan metode electrolessplating. Seperti pada foto SEM, terlihat adanya lekukanlekukan di permukaan plastik $A B S$ kemudian tertutup dengan lapisan logam diatasnya. Proses elektroplating krom bertujuan untuk menambah ketebalan lapisan, meningkatkan nilai kekerasan dan memberikan efek dekoratif pada plastik $A B S$. Besarnya ketebalan lapisan logam akan bertambah dengan semakin besar arus yang digunakan dalam proses elektroplating. Berbeda dengan kenaikan temperatur yang digunakan dalam proses elektroplating, ketebalan lapisan logam semakin rendah.

Ketebalan lapisan elektroplating dipengaruhi oleh rapat arus dan temperatur larutan yang digunakan. Rapat arus yang rendah mengakibatkan pergerakan ion dalam larutan sangat lambat sehingga waktu pembentukan inti kristal menjadi lama dan lapisan yang dihasilkan menjadi tipis. Peningkatan rapat arus sampai rapat arus kritis akan meningkatkan laju ion dan menghasilkan butiran logam yang halus. Peningkatan rapat arus yang melewati rapat arus kritis akan terjadi kekosongan ion pada daerah katoda sehingga permukaan menjadi lebih kasar. Peningkatan temperatur dapat menaikkan konduktivitas larutan sehingga tahanan larutan mengecil yang berati rapat arus akan naik dan laju reaksi pengendapan akan naik. Peningkatan temperatur akan meningkatkan laju difusi ion 


\section{Teknik}

Rahman, et al



sehingga endapan ion yang terjadi menjadi halus. Butiran yang halus menyebabkan logam mudah tekorosi. [9].

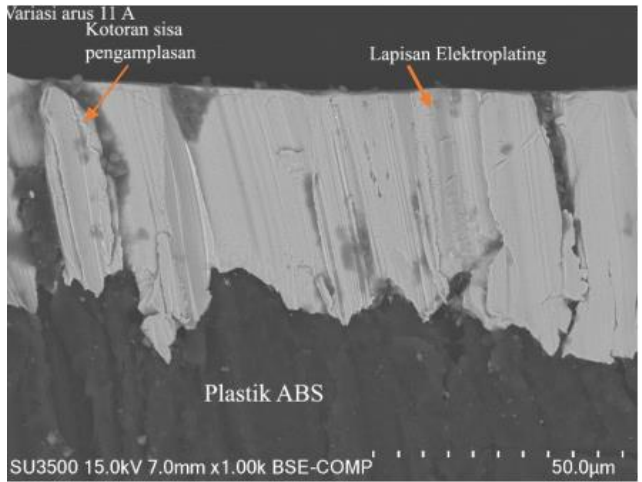

(a) Arus $11 \mathrm{~A}$

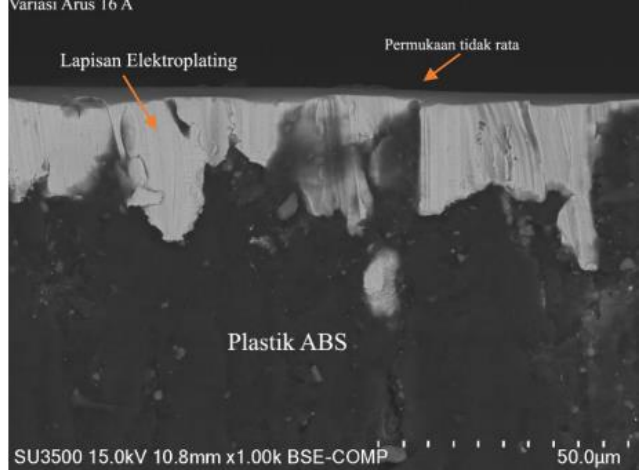

(b) Arus $16 \mathrm{~A}$

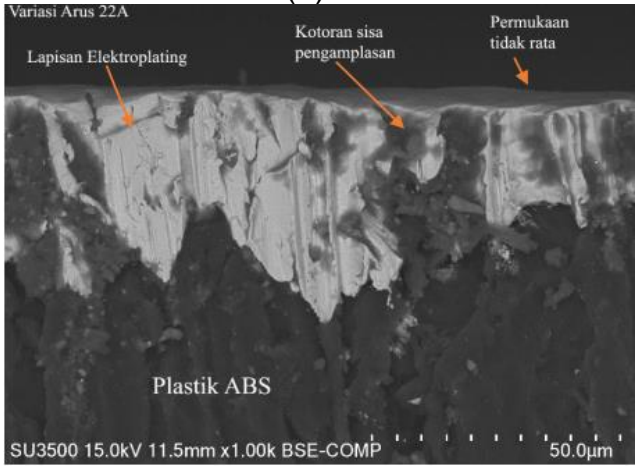

(c) Arus $22 \mathrm{~A}$

Gambar 3.2 Pengamatan SEM lapisan krom pada plastik ABS

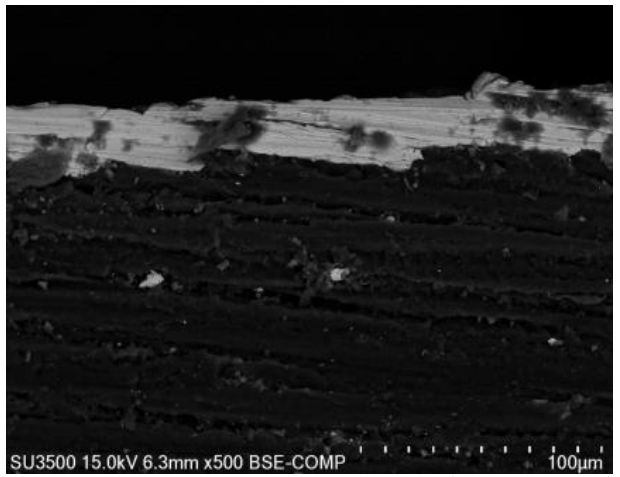

(d) Temperatur $55^{\circ} \mathrm{C}$

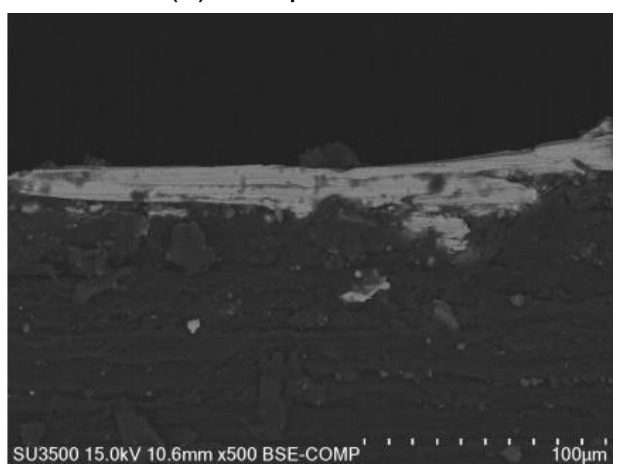

(e) Temperatur $65^{\circ} \mathrm{C}$

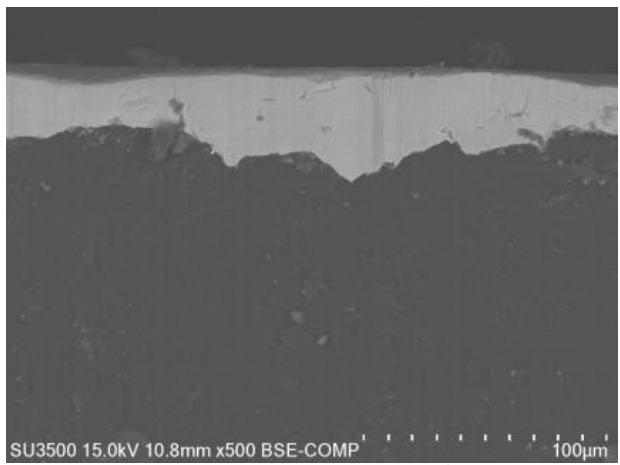

(f) Temperatur $75^{\circ} \mathrm{C}$

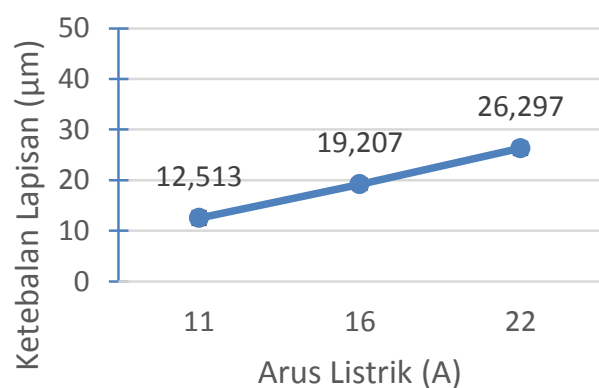

(a) Pengaruh arus listrik terhadap ketebalan lapisan

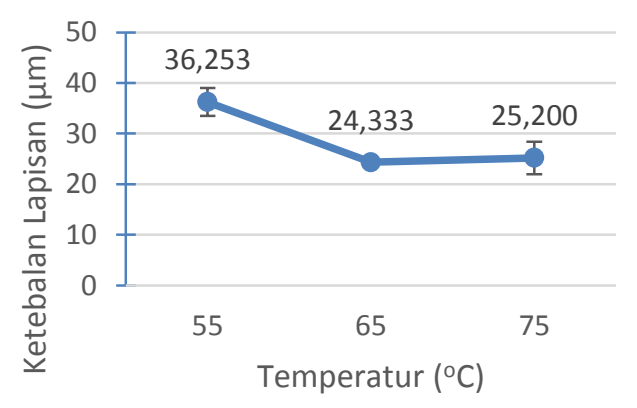

(b) Pengaruh temperatur terhadap ketebalan lapisan

\section{Gambar 3.2 Grafik ketebalan lapisan hasil elektroplating krom pada plastik ABS}




\subsection{Kekarasan Permukaan}

Peningkatan arus listrik pada proses elektroplating menyebabkan kekasaran permukaan menjadi semakin meningkat, seperti terlihat pada Grafik 3.3.a.

Berdasarkan Grafik 3.3.b menunjukkan semakin tinggi temperatur pelapisan maka kekasaran permukaan semakin rendah. Tingginya temperatur menyebabkan ion-ion dalam larutan menjadi semakin cepat bergerak dan mampu menempel semakin padat. Hal ini menyebabkan permukaan menjadi semakin halus. Kekasaran permukaan hasil elektroplating dengan menggunakan arus $11 \mathrm{~A}$ hasilnya hampir sama dengan proses elektroplating pada temperatur $75^{\circ} \mathrm{C}$ di sekitar $0,600 \mu \mathrm{m}$. Penggunaan arus $16 \mathrm{~A}$, nilai kekasarannya hampir sama dengan temperatur proses $65^{\circ} \mathrm{C}$ sekitar $0,455 \mu \mathrm{m}$ dan penggunaan arus proses $22 \mathrm{~A}$ nilai kekasarannya hampir sama dengan proses elektroplating pada temperatur $75^{\circ} \mathrm{C}$ sebesar $0,400 \mu \mathrm{m}$. Jika menggunakan arus rendah sebaiknya waktu pelapisan ditambahkan dan temperatur yang digunakan sebaiknya dikurangi agar mendapatkan hasil yang maksimal.

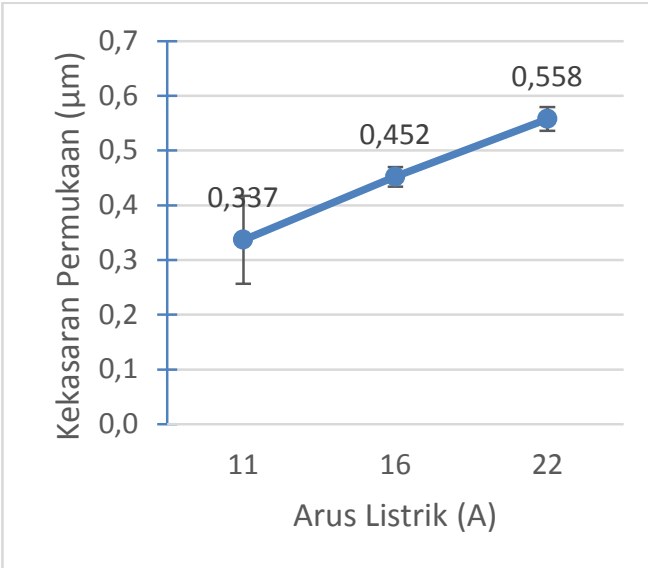

(a) Pengaruh arus listrik terhadap nilai kekasaran permukaan

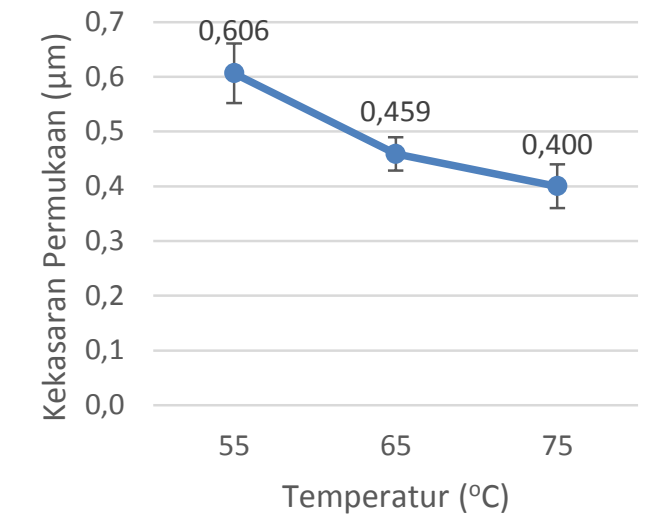

(b) Pengaruh temperatur terhadap nilai kekasaran permukaan

Gambar 3.3. Grafik nilai kekasaran permukaan hasil elektroplating krom pada plastik ABS

\subsection{Kekerasan Permukaan}

Nilai kekerasan plastik $A B S$ yang telah dilapisi krom dengan proses elektroplating menunjukkan terjadi peningkatan seperti terlihat pada Gambar 3.4 sebesar 33\% di mana kekerasan plastik $A B S$ sebesar 84 Shore Hardness type-D (SHD). Akan tetapi, variasi arus listrik dan temperatur tidak banyak mempengaruhi nilai kekerasan yaitu sebesar 111,80 SHD pada arus $11 \mathrm{~A}$, naik menjadi $114,13 \mathrm{SHD}$ pada penggunaan arus $16 \mathrm{~A}$, dan turun menjadi 112,83 SDH pada penggunaan arus 22 A seperti pada Gambar 3.4.a.

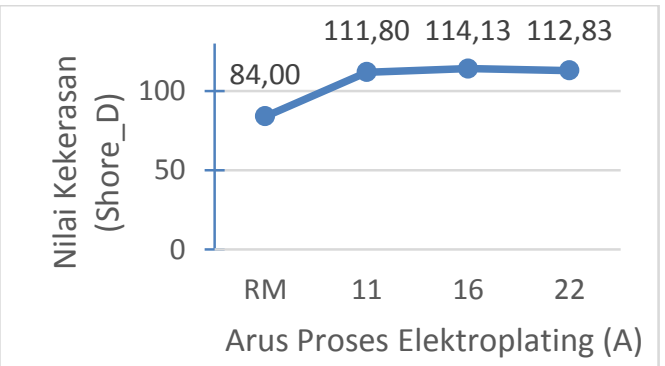

(a) Pengaruh arus listrik terhadap nilai kekerasan

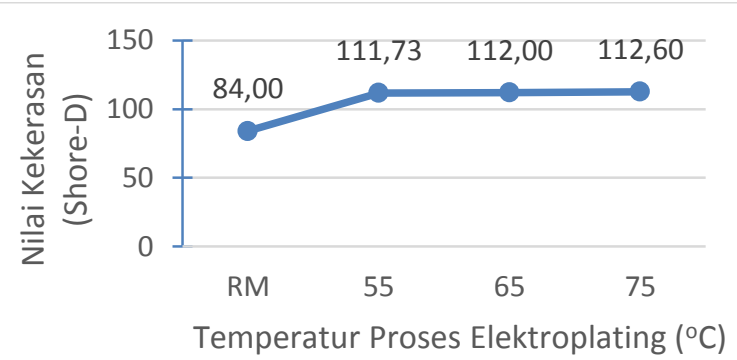

(b) Pengaruh temperatur terhadap nilai kekerasan

Gambar 3.4. Grafik nilai kekerasan hasil electroplating krom pada plastik ABS 
Penurunan nilai kekerasan disebabkan oleh arus yang besar dengan waktu dan temperatur normal mengakibatkan terbentuknya gelembung-gelembung yang semakin banyak dan arus yang semakin besar pula mengakibatkan temperatur menjadi lebih panas dan tidak stabil. Setelah lapisan menjadi jenuh ikatan ion-ion krom menjadi tidak stabil, ikatan ion-ion menjadi lemah sehingga kekerasan lapisan pada permukaan menjadi turun.

Peningkatan temperatur dapat meningkatkan nilai kekerasan walaupun kecil sampai $75^{\circ} \mathrm{C}$ sebesar 112,6 SHD seperti terlihat pada Gambar 3.4.b. Nilai kekerasan plastik $A B S$ setelah mendapatkan pelapisan krom pada temperatur $55^{\circ} \mathrm{C}$ sebesar $111,73 \mathrm{SHD}$ dan pada temperatur $65^{\circ} \mathrm{C}$ sebesar $112,0 \mathrm{SHD}$. Semakin tinggi temperatur proses pelapisan maka laju reaksi/gerakan ion-ion krom dalam larutan chromic acid yang digunakan sebagai elektrolit menjadi semakin cepat. Kenaikan temperatur meningkatkan energi kinetik ion-ion krom sehingga memungkinkan semakin banyak tumbukan ion krom menempel pada permukaan membentuk lapisan pada plastik. Lapisan krom menjadi lebih padat yang menyebabkan kerapatan permukaan pada spesimen meningkat sehingga kekerasan pada permukaan juga semakin meningkat. [10].

\section{KesimpULAN}

berikut:

Berdasarkan hasil penelitan yang telah dilakukan, diperoleh kesimpulan sebagai

1. Peningkatan arus listrik proses elektroplating dapat meningkatkan ketebalan lapisan. Ketebalan lapisan dengan arus 11 A sebesar $12,513 \mu \mathrm{m}$, arus 16 A sebesar 19,207 $\mu \mathrm{m}$ dan arus $22 \mathrm{~A}$ sebesar $25,222 \mu \mathrm{m}$. Proses elektroplating pada temperatur $65^{\circ} \mathrm{C}$ memiliki ketebalan lapisan paling tipis sebesar $24,333 \mu \mathrm{m}$, sedangkan pada temperatur $55^{\circ} \mathrm{C}$ dan $75^{\circ} \mathrm{C}$ sebesar $36,253 \mu \mathrm{m}$ dan $26,533 \mu \mathrm{m}$.

2. Peningkatan arus listrik proses elektroplating dapat meningkatkan kekasaran permukaan lapisan. Kekasaran permukaan pada arus $11 \mathrm{~A}$ sebesar $0,337 \mu \mathrm{m}$, pada arus $16 \mathrm{~A}$ sebesar $0.452 \mu \mathrm{m}$ dan pada arus $22 \mathrm{~A}$ sebesar $0,558 \mu \mathrm{m}$. Peningkatan temperatur proses pelapisan dapat menurunkan nilai kekasaran permukaan. Kekasaran pemukaan pada temperatur proses $55^{\circ} \mathrm{C}$ sebesar $0,606 \mu \mathrm{m}$, pada temperatur $65^{\circ} \mathrm{C}$ sebesar 0,459 $\mu \mathrm{m}$, dan pada temperatur $75^{\circ} \mathrm{C}$ sebesar $0,400 \mu \mathrm{m}$.

3. Elektroplating krom pada plastik $A B S$ meningkatkan nilai kekerasan material, namun variasi arus listrik dan temperatur tidak banyak meningkatkan nilai kekerasan karena lapisan yang dihasilkan relatif tipis. Nilai kekerasan hampir sama dengan nilai kekerasan plastik $A B S$ sebesar 112 shore- $D$.

\section{Daftar Pustaka}

[1] Nurhajati, D.W., dan Saraswati, A., Studi Pelapisan Logam Pada Produk-Produk Plastik, Majalah Barang Kulit, Karet, dan Plastik, 1993, Vol. VIII, No. 15, pp. 66-70

[2] Yuniati. Optimasi Tahap Aktivasi pelapisan Logam Nikel Pada Plastik ABS, Jurnal Teknik Politeknik Negri Lhoksumawe, 2010, 10 (2): 1 - 4.

[3] Rahman, M.B.N., Sunardi, Erlangga, M.B., Pratama, M.F., Pengaruh Temperatur dan Waktu Etching Terhadap Karakeristik Fisik dan Mekanik Pelapisan Nikel pada Plastik ABS dengan Metode Elektrolessplating, Jurnal Rekayasa Energi Manufaktur, 2018, Vol.3, No.2, pp.61-69

[4] Topayung, D., Pengaruh Arus Listrik Dan Waktu Proses Terhadap Ketebalan Dan Massa Lapisan Yang Terbentuk Pada Proses Elektroplating Pelat Baja, Jurnal IImiah Sains, 2011, Vol. 11 (1), pp. 97-101.

[5] Santhiarsa, N., 2016. Pengaruh Temperatur Larutan Dan Waktu Pelapisan Elektroles Terhadap Ketebalan Lapisan Metal Di Permukaan Plastik ABS, Konferensi Nasional Engineering Perhotelan (KNEP) VII, Bali, 2016.

[6] Yulianto, S. R., dan E. Widodo, 2013. Analisa Pengaruh Variasi Temperatur Proses Pelapisan Nikel Krom Terhadap Kualitas Ketebalan Dan Kekerasan Pada Baja ST 40, Seminar Nasional Fakultas Teknik (SNFT) UMSIDA, 2013, pp. 145 - 159.

[7] Zohari, A., Kusmono, Pengaruh Komposisi Larutan, Variasi Arus Dan Waktu Proses Pelapisan Krom Pada Plastik ABS Terhadap Sifat Mekanis, Tesis, Teknik Mesin, Fakultas Teknik, Universitas Gajah Mada, Yogyakarta, 2013 
[8] Dini, J.W., Snyder, D.D., Modern Electroplating, $5^{\text {th }}$ Edition, Chapter 2. Electrodeposition of Copper, The Wiley Network, Wiley Press Room, 2010

[9] Akuan, A., Karakteristik Proses Pelapisan Emas Pada Plastik Resin ABS, Jurusan Metalurgi Unjani. 2008

[10] Santhiarsa, I N., (2010). Pengaruh Temperatur lapisan dan Waktu pelapisan Elektroles pada Proses Metalisasi Plastik ABS terhadap Kekerasan Lapisan,. Seminar Nasional Tahunan Teknik Mesin (SNTTM) ke-9 (pp. MIV-22). Palembang: Digital Prosiding SNTTM IX. 